\title{
Teaching hemodynamics via horticulture
}

\author{
Sylvain Boet, MD · Olivier Collange, MD • \\ M. Dylan Bould, MB ChB
}

Received: 2 January 2011/Accepted: 1 March 2011/Published online: 18 March 2011

(C) Canadian Anesthesiologists' Society 2011

\section{To the Editor,}

Hemodynamics is a core subject learned by all medical students and health care providers. Various analogies can be used when teaching the interaction between cardiac output, venous return, arterial pressure, and oxygen delivery. ${ }^{1-3}$ However, students may still be confused when they try to integrate these analogies into a single comprehensive mental model. Herein, we propose an "advance organizer", namely, gardening to teach hemodynamics to medical students. An advance organizer is an analogy-based educational tool that draws on information that is present prior to learning, typically intuitive knowledge or information with which all learners are familiar without any specific teaching. For example, everyone old enough to be a medical student should be familiar with watering flowers. Given this basic background information, the learner can organize and interpret new information - related to

This work should be attributed to Pôle Anesthésie, Réanimation Chirurgicale, SAMU, Hôpitaux Universitaires de Strasbourg, Strasbourg, France.

S. Boet, MD

Allan Waters' Family Patient Simulation Centre, St. Michael's Hospital, University of Toronto, Toronto, ON, Canada

O. Collange, MD ( $\square)$

Pôle Anesthésie, Réanimation Chirurgicale, SAMU, Hôpitaux Universitaires de Strasbourg, Strasbourg, France

e-mail: olivier.collange@chru-strasbourg.fr

M. D. Bould, MB ChB

Department of Anesthesiology, The Children's Hospital of Eastern Ontario, University of Ottawa, Ottawa, ON, Canada hemodynamic physiology - and integrate the new knowledge into the old information schema. ${ }^{4,5}$

Hemodynamics is like gardening. The garden (human body) is composed of blades of grass (cells) that need water (oxygenated blood). The gardener must operate a hand pump (heart) with a unidirectional valve (heart valves) that will water the whole lawn through a hose (vascular system). When the pump is operated, a jet of water is emitted from the pipe (systole) and reaches the most distant areas of the garden. When the pressure on the pump is released, the water is emitted from the hose at lower pressure (diastole). The gardener pumps at a certain frequency (heart rate) with a developed force (inotropy). The pressure of the jet of water also depends on the resistance of the pipe. The jet of water is characterized by flow and pressure. Pressure depends on both flow and resistance from the nozzle of the hose (pressure $=$ flow $\times$ resistance). The gardener must provide enough water pressure to reach all blades of grass in the lawn and must deliver sufficient flow to provide ample water to the whole lawn. Tissue oxygenation is represented by water (oxygenated blood) reaching the blades of grass (cells). The change in the color of the grass (lactatemia) is a very late test of the quality of irrigation. Any good gardener wants to make sure that the grass is watered sufficiently by testing the humidity in the soil (venous oxygen saturation $-\mathrm{SvO}_{2}$ ) to prevent the grass from turning yellow (hyperlactatemia). If the soil is dry (low $\mathrm{SvO}_{2}$ ), the grass will soon turn yellow (hyperlactatemia). If the grass is already yellow, watering is necessary, but watering too much can be more harmful than beneficial (ischemia-reperfusion phenomenon).

This advance organizer can be refined. A water pipe and arm pump activated by the gardener results in a pulsatile cardiac output, and excess water not absorbed by the grass returns to the pump, corresponding to venous return 
(the garden slopes). Finally, regional hemodynamics can be represented by specific types of plants, for example, the garden has a area for roses (brain) that is very sensitive to water deprivation (high oxygen consumption) compared with the rest of the garden represented by the grass. To operate the pump properly, the gardener himself must consume some fluid, filling his glass of water during diastole (coronary perfusion).

This advance organizer has at least two clear limitations: the water represents both the blood and the oxygen, and the advance organizer does not take into account cardiopulmonary interactions.

In conclusion, this advance gardening organizer is a simple theoretical tool that we use to teach medical students the basic principles of hemodynamics. Cardiovascular pathophysiology can easily be derived from this advance organizer.
Conflicts of interest None declared.

\section{References}

1. Permutt S, Riley RL. Hemodynamics of collapsible vessels with tone: the vascular waterfall. J Appl Physiol 1963; 18: 924-32.

2. Swain DP. The water-tower analogy of the cardiovascular system. Adv Physiol Educ 2000; 24: 43-50.

3. Burkhoff D, Alexander J Jr, Schipke J. Assessment of Windkessel as a model of aortic input impedance. Am J Physiol 1988; 255(4 Pt 2): $\mathrm{H} 742-53$.

4. Ausubel DP. The use of advance organizers in the learning and retention of meaningful verbal material. J Educ Psychol 1960; 51: 267-72.

5. Stone CL. A meta-analysis of advance organizer studies. J Exp Educ 1983; 51: 194-9. 